\title{
AUTOEVALUACIÓN Y AUTOCALIFICACIÓN DESDE LA EVALUACIÓN FORMATIVA. UNA PROPUESTA EN EDUCACIÓN PRIMARIA
}

Self-assessment and self-grading from formative assessment. A proposal in Primary Education.

Autoavaliação e autoclassificação, a partir da avaliação formativa. Uma proposta na Educação Primária

Marcos Herranz Sancho (1)

(1) Junta Castilla y León, España. Teléfono: 659595790. Correo electrónico: marcosancho26@gmail.com

\section{Resumen}

El objeto principal del presente trabajo es exponer el método de evaluación y calificación que llevamos a cabo con alumnos de Educación Primaria. Plantemos nuestra propuesta dividida en varias fases distintas analizando todo el proceso de enseñanza, aprendizaje, recogida de información, evaluación y calificación seguida por los alumnos y por el profesor. En cada una de las fases explicamos los instrumentos de evaluación formativa que utilizamos, cómo lo hacemos y las posibles variantes que pueden surgir dependiendo de los grupos de alumnos o situaciones que nos encontremos. Entendemos que este método de evaluación formativa y compartida es viable en las condiciones de trabajo habituales del docente, fomenta la participación del alumno, despierta su conciencia crítica y contribuye al desarrollo profesional del profesor.

Palabras clave: Autoevaluación; Evaluación Formativa; Participación

\section{Abstract}

The main objective of this paper is to present the method of assessment and grading that we carry out with our Primary Education students. Let us explain our proposal divided into several different phases analysing the whole teaching and learning process, gathering information, assessment and grading carried out by the students and the teacher. In each phase we explain the formative evaluation tools that we use, how we do it and the possible variants that can arise depending on the groups of students or 
situations that we encounter. In our view this method of formative and shared assessment is feasible in the usual working conditions of the teacher, encourages the student's participation, awakens his/her critical awareness and contributes to the professional development of the teacher.

Keywords: Self-assessment; formative assessment; participation

\section{Resumo}

O objetivo principal do presente trabalho é apresentar o método de avaliação e classificação realizado com alunos de Educação Primária. Apresentaremos a nossa proposta dividida em várias fases, analisando todo o processo de ensino, aprendizagem, recolha de informação, avaliação e classificação, seguida pelos alunos e pelo professor. Em cada uma das fases explicamos os instrumentos de avaliação formativa utilizados, como o fazemos e as possíveis variantes que podem surgir, dependendo dos grupos de alunos ou situações em que nos encontremos. Entendemos que este método de avaliação formativa e partilhada é viável nas condições de trabalho habituais dos docentes, fomenta a participação do aluno, desperta a sua consciência crítica e contribui para o desenvolvimento profissional do professor.

Palavras-chave: Autoavaliação; avaliação formativa; participação

\section{Las reglas del juego}

-Lo tenemos que tener claro nosotros. Para implantar un sistema de evaluación mediante autoevaluación y autocalificación hay que creer él y el los efectos que pueda causar en alumnos, profesor y proceso de enseñanza y aprendizaje.

-Explicación del Sistema de evaluación. Será una tarea fundamental y obligatoria (Decreto 26/2016) al principio de comenzar la experiencia. Habrá que explicar y recordar conceptos constantemente. Podremos ejemplificar con experiencias reales vividas en el aula.

-Concreción de los criterios de evaluación. Es una de las primeras tareas (Decreto 26/2016) y será un referente para alumnos, profesor y familias. En mi opinión los alumnos han de participar en la elaboración de los criterios de evaluación junto con el profesor para fomentar a motivación y la implicación.

Yo he utilizado una escala gráfica (sistema de caritas o emoticonos: muy contenta, contenta, seria y triste) y los tengo todo el curso puestos en un lugar visible del aula. 
-Concreción de los criterios de calificación. Los alumnos han de saber que será lo que les pedimos para obtener las distintas calificaciones. Hemos de concretar qué será lo pedimos para que el alumno obtenga un aprobado en la asignatura, para el bien, para el notable y para el sobresaliente. Se pueden hacer a través de instrumentos como escalas graduadas o rubricas. Yo los tengo todo el curso puestos en un lugar visible del aula.

-Información sobre los criterios de promoción. En enseñanza primaria la normativa no los concreta aunque es muy posible que estén contemplados en los Reglamentos de Régimen Interior de los centros. Se informará de ellos al comienzo del curso tanto a los alumnos como a las familias.

- Conceptos clave de cada unidad. Al comenzar cada Unidad Didáctica los alumnos copian en sus cuadernos los conceptos clave de la unidad. Son los referentes sobre los cuales se tendrán que autoevaluar al final de dicha UD. Estos conceptos clave derivan de los estándares de aprendizaje evaluables (Decreto 26/2016).

\section{A trabajar}

-Actividades de aprendizaje competenciales. Se programan actividades manipulativas, cooperativas, colaborativas, integrando las tics, fomentando la interacción, con dinámicas jugadas y potenciando el buen clima de aula.

-Agrupamientos. Generalmente las sesiones de clase comienzan en gran grupo, siguen en pequeño grupo, pasan a parejas y terminan en individual. Esta estructura es variable en función de diversos aspectos.

-La coevaluación. Cuando terminamos las actividades hacemos coevaluación (individual o grupal) basándonos en los criterios de evaluación que antes hemos acordado (emoticonos de caritas). Si no hay acuerdo entre los alumno, ambos hablan con el profesor para resolver la situación.

-Sistema de observación. Se establece un turno mediante el cual se presta especial atención a tres o cuatro alumnos en cada sesión de clase para tener varias informaciones de cada alumno en cada UD y trimestre.

\section{La recogida de información}

Se trata de recoger información para que posteriormente podamos dar feed-back al alumno y mostrar nuestros acuerdos y/o desacuerdos con él. Para ello utilizamos varios instrumentos de recogida de información. 
-Cuaderno diario del profesor. Es un cuaderno diario en el que el profesor va anotando los aspectos que considera más destacables. Pueden ser datos de un alumno en concreto, del método, de la sesión... Sólo es para aspectos destacados y no es necesario anotar todos los días si no se considera.

-Ficha de observación grupal básica. Se trata de una tabla de doble entrada en la que en las filas figuran los nombres de los alumnos y en las columnas los aspectos a observar. Es libre, muy abierta y sirve para observar cualquier aspecto que queramos (lectoescritura, cálculo, exposiciones...).

-Ficha de observación grupal competencial. Es una ficha más compleja que la anterior. Está basada en las cuatro dimensiones competenciales (saber, saber hacer, saber estar y saber ser) (Gonzáles Arévalo 2016). En las columnas se ponen los nombres de los alumnos y en las filas diferentes aspectos relacionados con cada una de las dimensiones competenciales. Su uso requiere ser muy constante en el registro de los datos. La información que proporciona resulta de gran calidad.

\section{La valoración del trabajo}

-Cuestionarios de autoevaluación. Se pasan a los alumnos al final da cada Unidad Didáctica. Los alumnos tienen que valorar sus aprendizajes en función de los criterios de evaluación establecidos (caritas de emoticonos muy contenta, contenta...). Los aspectos que los alumnos se han de valorar son los conceptos clave copiados en el cuaderno al comienzo de la Unidad. El profesor los leerá y se los devolverá a los alumnos mostrando sus acuerdos y/o desacuerdos basándose en la información previamente recogida.

-Evaluación compartida. Los alumnos analizan los cuestionarios y se produce una breve entrevista entre el profesor y el alumno para aclarar posibles dudas y llegar a acuerdos sobre la evaluación (López 2006).

\section{EI salto a la calificación}

-Fichas de autocalificación. Constan de una escala graduada en la que aparecen los distintos criterios necesarios para obtener las distintas calificaciones (criterios de calificación ya conocidos). Para realizarla los alumnos tendrán en su poder los distintos cuestionarios de autoevaluación realizados a lo largo del trimestre. En estas fichas hay 
una parte de proposición de la autocalificación y otra parte de justificación de la misma. El alumno tendrá que justificar su calificación de forma razonada y sincera.

-Calificación dialogada. Cuando el alumno se propone una calificación determinada y la justifica, se produce una breve entrevista con el profesor para llegar a acuerdos sobre la calificación (López 2006). En esta entrevista el profesor manifiesta su acuerdo y/o desacuerdo con el alumno.

- Acuerdos y desacuerdos. Si en la calificación dialogada se producen acuerdos se pone la calificación acordada entre profesor y alumno. Si no hay acuerdo la decisión se traslada al grupo clase. Los alumnos votarán y esa decisión será respetada.

\section{El informe final}

-La información a las familias y a los alumnos. Junto con la entrega de las calificaciones trimestrales entregaremos a las familias un informe que incluirá el grado de adquisición de las competencias (Decreto 26/2016). Mostraremos los puntos fuertes, los aspectos a mejorar y unas recomendaciones.

\section{Referencias}

Decreto 26/2016. (21 de julio de 2016). Por el que se establece el currículo y se regula la implantación, evaluación y desarrollo de la Educación Primaria en la Comunidad de Castilla y León. Boletín Oficial de Castilla y León.

González Arévalo, C. (2016). ¿Por dónde debo empezar? En Lleixá Arribas, T. y Sebastiani Obrador, E. M. (Coord.), Competencias clave y Educación Física (pp. 63-72). Barcelona: Inde.

Ley Orgánica 8/2013. (9 de diciembre de 2013). Para la mejora de la calidad educativa (LOMCE). Boletín Oficial del Estado.

López Pastor, V. M. (Coord.) (2006). La evaluación en educación Física. Revisión de los modelos tradicionales y planteamiento de una alternativa: la evaluación formativa y compartida. Madrid: Miño y Dávila. 